\title{
An investigation into the effects of, and interaction between, heel height and shoe upper stiffness on plantar pressure and comfort.
}

\author{
J.M.A. Melvin ${ }^{1}$, C. Price ${ }^{1}$, S. Preece ${ }^{1}$, C.J. Nester ${ }^{1 *}$, D. Howard ${ }^{2}$ \\ ${ }^{1}$ School of Health Sciences, University of Salford, Salford, UK.
}

${ }^{2}$ School of Computing, Science \& Engineering, University of Salford, Salford, UK.

*Corresponding author: Dr Carina Price: c.l.price@salford.ac.uk

Dr Jonathan Melvin; School of Health Sciences, Room PO33, University of Salford, Salford, UK, M6 6PU.

Dr Carina Price; School of Health Sciences, Room PO33, University of Salford, Salford, UK, M6 6PU.

Dr Steven Preece; School of Health Sciences, Room PO28, University of Salford, Salford, UK, M6 6PU.

Professor Christopher Nester; School of Health Sciences, Room PO32, University of Salford, Salford, UK, M6 6PU.

Professor David Howard; School of Computing, Science \& Engineering, Room UG6, Newton Building, University of Salford, Salford, M5 4WT. 


\section{An investigation into the effects of, and interaction between, heel height and shoe upper stiffness on plantar pressure and comfort.}

High heeled shoes remain popular, nevertheless it is not clear what influence manipulating characteristics of this footwear has on their functioning. It is accepted that shoe features other than heel height can affect plantar pressures. However, few investigations have compared such features, and none have compared the influence of modifying upper material stiffness, whilst systematically increasing heel height. A firm understanding of the interactions of footwear properties is essential to ensure that footwear designers can optimise design for the comfort and health of the wearer. This paper investigates a feature that is known to reduce comfort (heel height) and a feature that is easy to change without affecting aesthetics (material stiffness) to better understand the effects of their interaction on plantar pressure and comfort. Sixteen female participants with experience wearing high heels wore a range of shoes with five effective heel heights $(35-75 \mathrm{~mm})$ and two upper materials (with different stiffness). In-shoe plantar pressure was recorded and participants completed a comfort questionnaire. Increasing heel height increased plantar pressure under the metatarsal heads, while reducing pressure in the hallux and heel. Higher heel heights also lead to increased discomfort, particularly in the toes where discomfort increased $154.3 \%$ from the 35 to $75 \mathrm{~mm}$ heels. Upper stiffness did not affect plantar pressure. However, stiffer uppers significantly increased reported discomfort, most notably on top of the foot $(108.6 \%)$, the back of the heel $(87.7 \%)$, the overall width $(99 \%)$, and the overall comfort (100.7\%). Significant interaction effects between heel height and upper material existed for comfort questionnaire data. Manipulating heel height alters plantar pressure and comfort, and choice of upper material is paramount to achieving wearer comfort in heels.

Keywords: High heels; footwear; plantar pressure; material stiffness; effective heel height, uppers 


\section{Background}

Improving footwear comfort is a complex objective due to the many interactions that can influence it (e.g. heel height and upper material) and the large variations in the shape and properties of wearers' feet. In addition to these quantitative measures, each wearer has different expectations and preferences which define their interpretation of what is comfortable (Kouchi, 2011). Furthermore, past research attempting to investigate comfort in different footwear designs has often failed to adequately control variables between shoes being compared (e.g. high heeled shoes compared to sneakers (Mandato and Nester, 1999)). Such studies show whether there is a difference in comfort between shoe styles but cannot explain how the shoe design features are implicated in any differences. Other studies systematically vary one footwear characteristic, such as heel height (Worobets, Nigg and Stefanyshyn, 2009), or insert hardness (Mundermann, Nigg, Stefanyshyn, \& Humble, 2002). However, a shoe design can be altered in many ways and many of these characteristics and their interactions during gait are yet to be considered in the literature. During standing it has been shown that interactions of the footbed characteristics are also important when testing with a footbed machine (Witana, Goonetilleke, Au, Xiong, \& Lu, 2009). The lack of systematic investigation of individual variables and interactions during walking might stifle the development of comfortable heeled shoe designs.

Wearing shoes with a high heel affects biomechanics during gait; plantar pressure distribution (Cong, Luximon, \& Zhang, 2008), foot dimensions (such as length) and movement and the damping characteristics of the foot (via making the foot more rigid through the windlass mechanism) (Hicks, 1954; Levangie and Norkin, 2001). During walking increasing heel height plantarflexes the foot, reduces its 
functional length, increases load under the forefoot (Mandato and Nester, 1999; Nyska, McCabe, Linge, \& Klenerman, 1996; Snow, Williams, \& Holmes, 1992) and reduces load under the heel (Hong, Lee, Chen, Pei, \& Wu, 2005; Nyska, et al., 1996). Increases in forefoot pressure are focused on the medial side and there is a corresponding reduction in lateral forefoot pressure (Hong, et al., 2005; Ko et al., 2009; Lee and Hong, 2005; Mandato and Nester, 1999; Nyska, et al., 1996; Wang and Li, 2008). The vertical and anteroposterior ground reaction forces also increase (Ebbeling, et al., 1994; Hong, et al., 2005; Snow and Williams, 1994; Stefanyshyn, Nigg, Fisher, O'Flynn, \& Liu, 2000), there is an increased impact force (Lee and Hong, 2005), knee flexion moment (Lythgo, Craze, Raj, \& Y, 2017), reduced time to maximum plantar pressure (Snow, Williams, \& Holmes, Jr., 1992), and higher forcetime and pressure-time integrals under the medial forefoot (Nyska, et al., 1996). High heeled shoes therefore fundamentally change the way the foot interacts with the ground, however, there is little research that shows how the changes occur across incremental variations in heel height. Consideration of how these changes may be offset by interactions with other footwear design characteristics is also key.

In addition to influencing the biomechanics of the wearer, high heel shoes also affect comfort (Ebbeling, Hamill, \& Crussemeyer, 1994; Worobets, Nigg and Stefanyshyn, 2009). Qualitative data reports increased discomfort with increased heel height (Hong, et al., 2005; Lee and Hong, 2005). To offset this discomfort, past authors have highlighted that the design of the shoe plantar surface can be optimised, particularly the heel wedge angle and heel seat length are important footwear characteristics relating to perceived feeling (Witana, Goonetilleke, Au, Xiong, \& Lu, 2009). In addition, alongside comfort, stability has been identified as a key variable for reported wearer preference in high heels (Kouchi, 2011). The optimisation of heel 
height and its interaction with related characteristics can impact on comfort and the quantification of this effect in a systematic study design is therefore essential to produce comfortable footwear.

Aspects related to the upper of the footwear would also be expected to affect reported comfort of wearers and biomechanical outcomes. In women's dress shoes, the toe-box shape has been demonstrated to alter plantar and inter-digital pressures (Branthwaite, Chockalingam, \& Greenhalgh, 2013). The volume of a shoe upper has also been implicated as a risk factor for reduced foot health and pain when wearing medical-grade footwear (Hurst, Branthwaite, Greenhalgh and Chockalingham, 2017), which is a function of both upper shape and material. A shoe that is too tight is undesirable from comfort and health perspectives (Snow, Williams, \& Holmes, Jr., 1992; Wu 1996) with higher pressures on the dorsal foot linked to lower reported comfort in athletic shoes (Herbaut et al., 2016). The upper therefore provides an obvious footwear characteristic to modify and increase volume to improve comfort of the wearer and potentially reduce objective variables such as plantar pressures. However, conversely, an upper that does not sufficiently grip the foot will be unable to prevent the foot sliding inside the shoe (Herbaut et al., 2016). It is not clear if upper material characteristics affect plantar pressure nor comfort in high heels because they have never been investigated as independent variables in systematic study designs. Manipulating the material of the upper also offers the opportunity of altering the comfort of the footwear without changing the aesthetics of the design.

The aim of this study was to investigate the individual effects of increased heel height and upper stiffness on plantar pressure and comfort and any interaction between these two design factors. 


\section{Methods}

Institutional ethical approval was granted by the University of Salford Health Science ethics committee and 16 females with UK size 5 feet were recruited from the student and staff populations (age 27.4 (7.73) years, weight $57.6(5.25) \mathrm{kg}$, height 163.16 $(5.47) \mathrm{cm})$. Footwear was designed and manufactured specifically for this investigation and to manage costs this was the only size in which test shoes were produced. All participants were free of lower limb injuries and medical conditions known to affect gait. All participants self-reported that they were able to walk for 1.5 hours unaided and gave written informed consent to participate in this research.

To measure comfort the questionnaire used by Mundermann, Nigg, Stefanyshyn, \& Humble (2002) was adapted to better reflect appropriate terminology and experiences wearing high heeled shoes. Participants marked $150 \mathrm{~mm}$ visual analogue scales with anchor words "very comfortable" and "not comfortable". Scales were worded "how do you rate the comfort ......." and completed for: overall comfort; width comfort; length comfort; sole in the heel region; back of the heel; top of the foot; under the foot arch; ball of the foot (sides); ball of the foot (sole); comfort of the toes. This was completed for each shoe immediately after the trial in which pressure data was collected while the shoe was still being worn. The methodology did not utilise repeated walks in a control shoe as recommended by Mundermann, Nigg, Stefanyshyn, \& Humble (2002), however, prior to testing a repeatability study with 4 participants completing the questionnaire 4 times over 2 days with different shoes worn before the condition in question identified a maximum deviation in response of $23 \pm 15$ points and an average of $18 \pm 13$ points for a wedge heeled shoe. Additionally, participants wore the $55 \mathrm{~mm}$ softer upper shoe and completed the comfort scale three 
times for this shoe to assess the repeatability of results within this cohort. Past research had shown that participants show good reliability at scoring footwear comfort after 6 conditions (Luo et al., 2009), thus the testing was divided into equal sections with the control at the beginning, middle, and end so that this recommendation was not exceeded. This $55 \mathrm{~mm}$ softer upper shoe was chosen as the control because it represented the middle range of heel height. The second rating of this shoe was utilised as the outcome comfort score for that shoe condition and all scores were normalised in accordance with Witana, Goonetilleke, Au, Xiong, \& Lu (2009).

In-shoe plantar pressure was recorded using the Pedar-X system (Novel $\mathrm{GMbH}$, Munich, Germany). The in-soles utilised were calibrated prior to use utilising a bladder system following the manufacturer's instructions. The plantar pressure data was recorded and derived for the following regions: 1st metatarsophalangeal joint (MTP1), 2nd-4th metatarsophalangeal joints (MT24), the hallux, 5th metatarsophalangeal (MT5), the heel, and the midfoot in accordance with (Chapman et al., 2013). This data was collected and processed following the guidelines recommended by Melvin, Preece, Nester, \& Howard (2014). This included the use of two pairs of tc-timing system light gates (Brower Timing Systems, Draper, Utah, USA), which were positioned $12 \mathrm{~m}$ apart and used to measure walking speed, which was controlled at $1.2 \mathrm{~m} . \mathrm{s}^{-1} \pm 5 \%$. There was a further $3.5 \mathrm{~m}$ before and after the timing gates to allow acceleration and deceleration areas either side of the measurement steps. Participants were provided with verbal feedback to increase or decrease their speed if it did not match the required speed.

There were 5 heel heights investigated: $35,45,55,65,75 \mathrm{~mm}$ (Figure 1). All shoes had the same last contact point, and the same amount of sole material under the forefoot. These heights were chosen to ensure that the effects on pressure and 
comfort due to high heels could be seen over a wide yet typical range, whilst attempting to keep the total number of shoes to a practical limit to avoid fatiguing participants. Each shoe was made in a leather and a suede upper to provide variation in upper stiffness. On completion of the data collection, destructive tests were conducted by an independent footwear testing organisation (INESCOP, Spain) to measure upper material stiffness (Table 1); identifying the leather condition as more stiff. Footwear conditions were worn by participants in a random order generated by a Matlab (Version 8, Mathworks, Natick, MA, USA) randomisation script, except for the $55 \mathrm{~mm}$ softer upper show which was worn three times, at regular intervals starting with the first test and finishing on the last. Participants walked a minimum of 30 steps for the data collection following a minimum of 166 for familiarisation as recommended by Melvin, Preece, Nester, \& Howard, (2014).

Figure 1 near here

Table 1 near here

The statistical analysis for this study was completed using SPSS statistics software package (version 22; IBM Corp., Armonk, NY, USA). The analysis was a within-within (two way) 5x2 repeat measure ANOVA design, to investigate the main effect of the two intra-subject factors (heel height and material stiffness) on plantar pressure and material stiffness, and the interactions between these independent variables. Locations of significant effects were found using post-hoc pairwise comparisons with a Bonferroni adjustment, a $p$ value of .05 was chosen to denote significance. 


\section{Results}

\section{Plantar pressure}

There was a statistically significant effect of increasing heel height on plantar pressure, but no effect of upper material (Table 2). Increasing heel height reduced plantar pressures in the hallux and heel and increased pressure in MTP1 and MT24 regions (Figure 2). There were no significant interactions between material stiffness and heel height and plantar pressure in the foot regions tested. The data from the MT5 and the midfoot were not included in analysis because data were lower than the recommended operating rage of the pressure insole sensors $(<20 \mathrm{kPa})$ in these regions for more than $1 / 10$ of the trials.

\section{Table 2 near here}

Figure 2 near here

\section{Comfort questionnaire}

The repeated measures of comfort within the control shoe, did not differ significantly for the repeat tests 2 and 3 of the control shoe, for example "overall comfort" differed by a maximum of 16 points between conditions of the same footwear. Altering heel height significantly affected reported comfort (Table 3) with only the back of the heel unaffected $(p=.116)$. Altering upper material significantly affected comfort in the majority of foot regions (Figure 3). Increased material stiffness (leather versus suede) resulted in a $68 \%$ increase in discomfort at the "ball sides" (medial and lateral sides of the metatarsal heads) and $63.2 \%$ increase at the "ball sole" (plantar surface of metatarsal heads). The only region to not be associated with a significant effect on 
comfort was "under the arch" $(p=.081)$. There was a significant interaction for heel height"material stiffness on "ball sole" $(p=0.003 F(4,56)=4.440)$, "overall length" $(p=0.001 \mathrm{~F}(4,56)=5.284)$, and "under the arch" $(p=0.024 \mathrm{~F}(4,56)=3.039)$ (Figure 3). For the comfort scales the soft upper increased in discomfort relatively consistently with heel heights, particularly for "overall length" and "under the arch" whereas in the stiff upper discomfort peaked in the $45 \mathrm{~mm}$ heel condition with scores more similar to the $75 \mathrm{~mm}$ heel for "overall length" and the $65 \mathrm{~mm}$ heel for "under the arch" and "ball sole".

Table 3 near here

Figure 3 near here

\section{Discussion}

The aim of this study was to improve our understanding of the effect that heel height and shoe upper stiffness have on plantar pressure and comfort. The research has increased our understanding relating to which effective heel heights differ significantly from each other in terms of recorded plantar pressures and subjective comfort scores.

The regional plantar pressure results (peak pressures) recorded in this study replicate the ranges identified within existing research in high heeled footwear (Speksnijder et al., 2005; Yin et al., 2016; Wang and Li, 2005). Previous research reports that, generally, increasing heel height increases plantar pressure under the forefoot and reduces pressure at the heel (Speksnijder et al., 2005; Wang and Li, 2005). This was reflected in this study with higher pressures in the metatarsal regions as heel height increased, for example in the $75 \mathrm{~mm}$ heel condition, pressures in the 
MTP1 and MTP24 region were a mean $106 \mathrm{kPa}$ and $69 \mathrm{kPa}$ higher than in the $35 \mathrm{~mm}$ heel respectively. Increasing heel height significantly decreased plantar pressure in the heel, particularly for the $75 \mathrm{~mm}$ condition which differed significantly to the 35,45 and $55 \mathrm{~mm}$ conditions. Contrary to the rest of the forefoot, and previous work in stiletto heels with a narrow design (Mandato and Nester, 1999; Nyska, et al., 1996; Snow, et al., 1992), in this study the hallux experienced a reduction in pressure between both the 35 and $45 \mathrm{~mm}$ (mean $41 \mathrm{kPa}$ ) and the 65 and $75 \mathrm{~mm}$ (mean $35 \mathrm{kPa}$ ) conditions. This is perhaps because, unlike in this study, prior work tested shoes that had a narrow toe box which would further limit space for the toes compared to the shoes tested here, thus reducing the contact areas and increasing pressures (Branthwaite, Chockalingam, \& Greenhalgh, 2013). Similarly, stiletto shoes have a narrower heel design and may have required the wearers to further stabilise their foot utilising their hallux and therefore increase reported pressures. However, prior work (Schwartz, Heath, Morgan, \& Towns, 1964) showed that whilst heel heights from $12.7 \mathrm{~mm}$ to $31.75 \mathrm{~mm}$ increased hallux pressure, increases from $31.75 \mathrm{~mm}$ to $50.8 \mathrm{~mm}$, akin to the heights used in this study, reduced pressure. Contrary to manipulating heel height, altering the upper material between leather and suede, and therefore the upper stiffness, in this study had no significant effect on plantar pressures recorded. The largest mean difference was in the hallux region, where the softer upper reduced pressure by $36 \%(p=.076)$ compared with the more stiff upper, however this value did not reach significance. This links to the aforementioned work where a larger volume for the forefoot can help alleviate pressures in the hallux region.

Concurrent with the biomechanical changes with high heels and previous literature, reductions in reported comfort were anticipated in wearers as heel height increased. In the current research, there was only one significant difference in comfort 
between a heel of $35 \mathrm{~mm}$ and less than $65 \mathrm{~mm}$ (overall length comfort), but there were 22 significant differences between shoes of $65 \mathrm{~mm}$ heel height or greater. Simiarly, Lee, Jeong, \& Freivalds (2001) found that women were most "inconvenienced" by heels that were $6-9 \mathrm{~cm}$ high and used this as a basis for their work. All but one of the regions (under the arch) showed a significant effect of upper material on reported comfort. Therefore the current research highlights that the choice of material is paramount to achieving wearer comfort in heels. However, as aforementioned, the influence of upper material was not apparent in the pressure data where a change in material yielded no significant subsequent change in plantar pressure. The results in this study show that the stiff upper was an average 29 points more uncomfortable than the soft upper. Differences were largest in the scale relating to the "Foot top" (39.4 points) and smallest relating to the sensation "Under the arch" (21.0 points).

The current data suggests that pressure and comfort are not coupled as other researchers have previously shown (Che, Nigg, \& de Koning, 1994; Jordan, Payton, \& Bartlett, 1997). That it is possible to change comfort without changing plantar pressure is supported by Wegener, Burns \& Penkala (2008) and Clinghan, Arnold, Drew, Cochrane, \& Abboud (2008) who also found no relationship between comfort and plantar pressure data. One additional factor affecting comfort might be the dorsal pressures (Hagen, Homme, Umlauf, \& Hennig, 2010; Jordan, et al., 1997), and indeed large differences in subjective comfort between the upper materials were scored in regions related to the dorsal foot surface ("foot top" and "ball sides"). If we had been able to record dorsal pressures we may have anticipated changes in these variables, similar to those reported by Herbaut et al. (2016) in athletic shoes with different lace tightness. Our subjective results allude to the perceived sensation of the upper being an important factor to consider when designing high heels and significant in terms of 
overall comfort perception. Alternatively, upper stiffness might be more important at heel heights not tested in this study, or in other styles of shoe.

This study was the first to manipulate upper material stiffness at the same time as heel height therefore helping footwear designers identify how aspects can be manipulated concurrently to manage wearer experiences and sensations. There was significant interaction between heel height and material stiffness on "ball sole", "overall length", and "under the arch" regions for the comfort scale. Combined these results allude to the potential of a less stiff upper to reduce discomfort, particularly at heel heights of 65 and $75 \mathrm{~mm}$. Footwear designers can directly implement this into a footwear design and use softer uppers to increase comfort in shoes with heels higher than $65 \mathrm{~mm}$ in height. A limitation to this work may be the application of the results specifically to wedge heels as the data was collected in this footwear style only.

To ensure easy comparison of the plantar pressures recorded in shoe conditions the current study utilised the well-established approach of dividing the foot into specific regions with pressure masks (Cavanagh, Hewitt and Perry, 1992). This provides anatomical relevance to the data analysis and enables the linking of pressure to comfort questionnaire data, which is also related to specific foot regions, but prevents finding trends within the masked areas and introduces boundaries in terms of functional units of the foot that may not exist. Furthermore, plantar pressure insoles record pressure exerted normally to the surface of the sensor. Since, a high heel forces the foot and insole to rest at an inclined position, the shear loads exerted on the measurement insole may change and the load conditions are therefore underspecified. This acts as a limitation to the recorded plantar pressure data and will also influence any implicit relationships between these variables and comfort questionnaire results. 


\section{Conclusions}

Consistent with previous research, an increase in plantar pressure in the forefoot occurred with increases in heel height, although not in the hallux region. Modifying shoe upper material had a significant interaction with heel height for comfort in the metatarsal heads and heel, this is therefore recommended as key to achieving wearer comfort in heeled footwear. Changes in pressure were not related to changes in comfort and there was no interaction effect between upper stiffness and pressure demonstrating that although higher heels with softer uppers may be more comfortable, this does not guarantee alleviated pressures.

\section{Declaration}

The study was funded through a doctoral scheme for JM with Reckitt Benckiser, owners of the Scholl Footwear Brand. The funding body had no role in the study design, data collection, analysis or interpretation.

\section{References}

Branthwaite, H., Chockalingam, N., \& Greenhalgh, A. (2013). The effect of shoe toe box shape and volume on forefoot interdigital and plantar pressures in healthy females. Journal of Foot and Ankle Research, 6(1), pp. 1-9.

doi:10.1186/1757-1146-6-28 
Chapman, J., Preece, S., Braunstein, B., Höhne, A., Nester, C., Brueggemann, P., \& Hutchins, S. (2013). Effect of rocker shoe design features on forefoot plantar pressures in people with and without diabetes. Clinical Biomechanics, 28(6), pp. 679-685. doi:10.1016/j.clinbiomech.2013.05.005

Che, H., Nigg, B. M., \& de Koning, J. (1994). Relationship between plantar pressure distribution under the foot and insole comfort. Clinical Biomechanics, 9(6), pp. 335-341. doi:10.1016/0268-0033(94)90062-0

Cong, Y., Luximon, Y., \& Zhang, M. (2008). Effect of Shank Curve of High-heeled Shoe on the Plantar Pressure Distribution. Apcmbe 2008: 7th Asian-Pacific Conference on Medical and Biological Engineering, 19, pp. 500-502.

Ebbeling, C. J., Hamill, J., \& Crussemeyer, J. A. (1994). Lower extremity mechanics and energy cost of walking in high-heeled shoes. J Orthop Sports Phys Ther, 19(4), pp. 190-196.

Hagen, M., Homme, A.-K., Umlauf, T., \& Hennig, E. (2010). Effects of Different Shoe-Lacing Patterns on Dorsal Pressure Distribution During Running and Perceived Comfort. Research in Sports Medicine, 18, pp. 176-187. doi:10.1080/15438627.2010.490180

Herbaut, A., Simoneau-Buessinger, E., Barbier, F., Cannard, F. \& Guéguen, N. (2016): A reliable measure of footwear upper comfort enabled by an innovative sock equipped with textile pressure sensors. Ergonomics, 59(10), pp. 1327-1334. Doi:DOI:10.1080/00140139.2016.1142122

Hicks, J. H. (1954). The mechanics of the foot. II. The plantar aponeurosis and the arch. Journal of Anatomy, 88(1), pp. 25-30.

Hong, W. H., Lee, Y. H., Chen, H. C., Pei, Y. C., \& Wu, C. Y. (2005). Influence of heel height and shoe insert on comfort perception and biomechanical 
performance of young female adults during walking. [Research Support, NonU.S. Gov't]. Foot \& Ankle International, 26(12), pp. 1042-1048.

Hurst, B., Branthwaite, H., Greenhalgh, A., and Chockalingham, N. (2017) Medicalgrade footwear: the impact of fit and comfort. Journal of Foot and Ankle Research, 10(2).

Jordan, C., Payton, C., \& Bartlett, R. (1997). Perceived comfort and pressure distribution in casual footwear. Clinical biomechanics (Bristol, Avon), 12, p S5.

Ko, P.-H., Hsiao, T.-Y., Kang, J.-H., Wang, T.-G., Shau, Y.-W., \& Wang, C.-L. (2009). Relationship between plantar pressure and soft tissue strain under metatarsal heads with different heel heights. Foot \& Ankle International, 30(11), pp. 1111-1116.

Kouchi, M. (2011). Factors for evaluating high-heeled shoe comfort. Footwear Science 3(S1), pp. S90-S92.

Lee, C. M., Jeong, E. H., \& Freivalds, A. (2001). Biomechanical effects of wearing high-heeled shoes. International Journal of Industrial Ergonomics, 28(6), pp. 321-326. doi:Doi 10.1016/S0169-8141(01)00038-5

Lee, Y. H., \& Hong, W. H. (2005). Effects of shoe inserts and heel height on foot pressure, impact force, and perceived comfort during walking. Appl Ergon, 36(3), pp. 355-362. doi:DOI 10.1016/j.apergo.2004.11.001

Levangie, P. K., \& Norkin, C. C. (2001). Joint structure and function: A comprehensive analysis (3rd ed.) Philadelphia: F. A. Davis Company. Lythgo, N., Craze, M., Raj, I. S., \& Y, L. (2017). Increased Shoe Heel Height Generates Greater Peak Knee Extension Moments than Fast Walking 
Speeds. 6th International Conference on the Development of Biomedical Engineering in Vietnam (BME6). Ho Chi Minh City, Vietnam: Springer. Mandato, M. G., \& Nester, E. (1999). The effects of increasing heel height on forefoot peak pressure. J Am Podiatr Med Assoc, 89(2), pp. 75-80.

Melvin, J. M. A., Preece, S., Nester, C. J., \& Howard, D. (2014). An investigation into plantar pressure measurement protocols for footwear research. Gait \& Posture, 40(4), pp. 682-687. doi:DOI 10.1016/j.gaitpost.2014.07.026

Mundermann, A., Nigg, B. M., Stefanyshyn, D. J., \& Humble, R. N. (2002).

Development of a reliable method to assess footwear comfort during running. [Comparative Study

Research Support, Non-U.S. Gov't]. Gait Posture, 16(1), pp. 38-45.

Nyska, M., McCabe, C., Linge, K., \& Klenerman, L. (1996). Plantar foot pressures during treadmill walking with high-heel and low-heel shoes. [Comparative Study]. Foot \& Ankle International, 17(11), pp. 662-666.

Schwartz, R. P., Heath, A. L., Morgan, D. W., \& Towns, R. C. (1964). A Quantitative Analysis of Recorded Variables in the Walking Pattern of Normal Adults. Journal of Bone and Joint Surgery-American Volume, 46(2), pp. 324-334.

Snow, R. E., \& Williams, K. R. (1994). High heeled shoes: their effect on center of mass position, posture, three-dimensional kinematics, rearfoot motion, and ground reaction forces. [Research Support, Non-U.S. Gov't]. Arch Phys Med Rehabil, 75(5), pp. 568-576.

Snow, R. E., Williams, K. R., \& Holmes, G. B., Jr. (1992). The effects of wearing high heeled shoes on pedal pressure in women. [Research Support, Non-U.S. Gov't]. Foot Ankle, 13(2), pp. 85-92. 
Speksnijder, C. M., Moonen, S. A., \& Walenkamp, G. H. (2005). The higher the heel the higher the forefoot-pressure in ten healthy women. The Foot, 15(1), pp. $17-21$.

Stefanyshyn, D. J., Nigg, B. M., Fisher, V., O'Flynn, B., \& Liu, W. (2000). The influence of high heeled shoes on kinematics, kinetics, and muscle EMG of normal female gait. Journal of Applied Biomechanics, 16(3), pp. 309-319.

Wang, L., \& Li, J. (2008). Gait characteristics and pressure distribution for barefoot and various heel height shoes during walking. ISBS-Conference Proceedings Archive.

Wegener, C., Burns, J., \& Penkala, S. (2008). Effect of Neutral-Cushioned Running Shoes on Plantar Pressure Loading and Comfort in Athletes with Cavus Feet:A Crossover Randomized Controlled Trial. The American Journal of Sports Medicine, 36(11), pp. 2139-2146. doi:10.1177/0363546508318191

Witana, C. P., Goonetilleke, R. S., Au, E. Y., Xiong, S., \& Lu, X. (2009). Footbed shapes for enhanced footwear comfort. [Research Support, Non-U.S. Gov't]. Ergonomics, 52(5), pp. 617-628. doi:10.1080/00140130802419503

Worobets, J.T., B.M. Nigg, and D.J. Stefanyshyn. (2009). Correlations between biomechanical variables and comfort ratings during high heeled gait. Footwear Science, 1(1), pp. S43-S44.

Wu, K.K. (1996) Morton's interdigital neuroma: a clinical review of its etiology, treatment,and results. The Journal of foot and ankle surgery, 35(2): pp. 112119. 
Table 1. Results from the destructive material tests of upper materials (ISO 5403-

1:2011, clause 6.1; IAO 17235:2011; ISO 3376:2011) conducted by INESCOP, Spain.

\section{Test Conducted}

Bovine Suede

(soft upper)
Bovine Leather

(stiff upper)

\begin{tabular}{|c|c|c|c|c|}
\hline \multirow{2}{*}{\multicolumn{5}{|c|}{ Leather Stiffness }} \\
\hline & & & & \\
\hline $2 \mathrm{~mm}$ compression & 1.7 & 2 & 6.6 & 7.2 \\
\hline $4 \mathrm{~mm}$ compression & 2 & 2.2 & 6.4 & 7.2 \\
\hline $\begin{array}{r}6 \mathrm{~mm} \text { compression } \\
\text { Mean }\end{array}$ & 2.2 & 2.3 & 6.5 & 7.4 \\
\hline
\end{tabular}

Softness * (mm distension)

\begin{tabular}{|c|c|c|c|}
\hline $\begin{array}{c}6.4 \\
6 \\
6.5\end{array}$ & $\begin{array}{r}7 \\
7 \\
\\
56.5\end{array}$ & $\begin{array}{l}4.6 \\
4.5 \\
4.5\end{array}$ & $\begin{array}{l}4.3 \\
4.3 \\
4.1\end{array}$ \\
\hline 25.4 & 19.8 & 18.5 & 19.5 \\
\hline $\begin{array}{c}57 \\
1.47\end{array}$ & $\begin{array}{c}49 \\
1.53\end{array}$ & $\begin{array}{c}51 \\
1.41\end{array}$ & $\begin{array}{l}39 \\
1.5\end{array}$ \\
\hline
\end{tabular}

Tensile Strength $\left(\mathrm{N} / \mathrm{mm}^{2}\right)$

Elongation at break (\%)

Thickness (mm) 
Table 2. Plantar pressure outcomes from significant heel height effects. Post-hoc comparisons are reported only for significant comparisons within heel height and following a significant ANOVA.

\begin{tabular}{|c|c|c|c|c|c|c|}
\hline \multirow{2}{*}{$\begin{array}{l}\text { Regional } \\
\text { pressure }\end{array}$} & \multicolumn{2}{|c|}{ Material } & \multicolumn{4}{|c|}{ Heel Height } \\
\hline & $\begin{array}{l}\text { ANOVA } \\
\text { outcome }\end{array}$ & $\begin{array}{c}\text { Increase } \\
\text { in } \\
\text { pressure } \\
(\%) \\
\end{array}$ & $\begin{array}{l}\text { ANOVA } \\
\text { outcome }\end{array}$ & $\begin{array}{c}\text { Post-Hoc } \\
\text { Significant } \\
\text { comparisons } \\
(\mathrm{mm})\end{array}$ & $\begin{array}{c}\text { Pressure } \\
\text { change } \\
(\%)\end{array}$ & $p$ value \\
\hline \multirow{7}{*}{ MTP1 } & & & & $35 \mathrm{v} 55$ & $14.3 \uparrow$ & 0.030 \\
\hline & & & & $35 \mathrm{v} 65$ & $41.4 \uparrow$ & $<.001$ \\
\hline & & & $p<.001$ & $35 v 75$ & $40.5 \uparrow$ & 0.003 \\
\hline & $\begin{array}{c} \\
F(1,14)=1.452\end{array}$ & NS & $F(1.803,25.242)=$ & $\begin{array}{l}45 v 65 \\
45 v 75\end{array}$ & $\begin{array}{c}29 \uparrow \\
282 \uparrow\end{array}$ & $<.001$ \\
\hline & & & & $55 \mathrm{v} 65$ & $23.7 \uparrow$ & $<.001$ \\
\hline & & & & $55 \vee 75$ & $22.9 \uparrow$ & 0.011 \\
\hline & & & & $35 v 55$ & $7.5 \uparrow$ & 0.029 \\
\hline \multirow{6}{*}{ MTP24 } & $p=0.558$ & & $p<.001$ & $35 v 75$ & $25.7 \uparrow$ & 0.003 \\
\hline & $F(1,14)=$ & NS & $F(1.477,20.678)=$ & $45 v 75$ & $20.2 \uparrow$ & 0.002 \\
\hline & 0.361 & & 18.444 & $55 \mathrm{v} 75$ & $19.7 \uparrow$ & 0.004 \\
\hline & & & & $65 v 75$ & $16.5 \uparrow$ & 0.001 \\
\hline & & & & $35 v 65$ & $15.9 \downarrow$ & 0.009 \\
\hline & $p=0.335$ & & $\begin{array}{c}p=0.002, \\
\text { s }\end{array}$ & $35 v 75$ & $24.8 \downarrow$ & $<.001$ \\
\hline Heel & $\begin{array}{c}r(1,14)= \\
0.996\end{array}$ & NS & $\begin{array}{c}F(2.0 / 1,28.990)= \\
7.472\end{array}$ & $45 v 75$ & $25.7 \downarrow$ & 0.005 \\
\hline & & & & $55 \mathrm{v} 75$ & $20.2 \downarrow$ & 0.043 \\
\hline & & & $p=0.010$ & $35 v 45$ & $15.8 \downarrow$ & 0.021 \\
\hline Hallux & $\begin{array}{c}F(1,14)= \\
3.660\end{array}$ & & $\begin{array}{c}F(1.569,21.968)= \\
6.429\end{array}$ & $65 v 75$ & $15.8 \downarrow$ & 0.030 \\
\hline
\end{tabular}

Where NS is not significant therefore not reported 
Table 3. Comfort questionnaire comparison (mean of both uppers) results for each of the questions asked (regions) for material (from soft to hard) and heel height (from low to high). Post-hoc comparisons are reported only for significant comparisons within heel height and following a significant ANOVA. 


\begin{tabular}{|c|c|c|c|c|c|c|}
\hline \multirow{2}{*}{$\begin{array}{l}\text { Region } \\
\text { from } \\
\text { question }\end{array}$} & \multicolumn{2}{|c|}{ Material } & \multicolumn{4}{|c|}{ Heel Height } \\
\hline & $\begin{array}{l}\text { ANOVA } \\
\text { outcome }\end{array}$ & $\begin{array}{c}\text { Increase } \\
\text { in } \\
\text { discomfort } \\
(\%)\end{array}$ & $\begin{array}{l}\text { ANOVA } \\
\text { outcome }\end{array}$ & $\begin{array}{c}\text { Post-Hoc } \\
\text { Significant } \\
\text { comparisons } \\
(\mathrm{mm})\end{array}$ & $\begin{array}{c}p \\
\text { value }\end{array}$ & $\begin{array}{c}\text { Increase } \\
\text { in } \\
\text { discomfort } \\
(\%)\end{array}$ \\
\hline Ball sides & $\begin{array}{c}p=0.001 \\
\mathrm{~F}(1,14)=15.55\end{array}$ & 68 & $\begin{array}{c}p=0.002, \\
F(4,56)=4.69\end{array}$ & $\begin{array}{l}35 \vee 75 \\
45 \vee 75\end{array}$ & $\begin{array}{l}0.022 \\
0.021\end{array}$ & $\begin{array}{l}98.4 \\
45.1\end{array}$ \\
\hline Ball sole & $\begin{array}{c}p=0.006, \\
F(1,14)=10.7\end{array}$ & 63.2 & $\begin{array}{c}p=<.001 \\
F(4,56)= \\
7.268\end{array}$ & $\begin{array}{l}35 \vee 75 \\
55 \vee 65 \\
55 \vee 75\end{array}$ & $\begin{array}{l}0.029 \\
0.026 \\
0.003\end{array}$ & $\begin{array}{l}98.2 \\
73.5 \\
94.1\end{array}$ \\
\hline $\begin{array}{l}\text { Foot top } \\
\text { (dorsal } \\
\text { surface) }\end{array}$ & $\begin{array}{c}p=0.000 \\
F(1,14)=41.075\end{array}$ & 108.6 & $\begin{array}{c}p=<.001 \\
F(4,56)= \\
7.956\end{array}$ & $\begin{array}{l}35 \vee 65 \\
35 \vee 75\end{array}$ & $\begin{array}{l}0.011 \\
0.000\end{array}$ & $\begin{array}{c}88.7 \\
105.1\end{array}$ \\
\hline Heel back & $\begin{array}{c}p=0.000 \\
F(1,14)=30.714\end{array}$ & 87.7 & $\begin{array}{c}p=0.116 \\
F(4,56)= \\
1.942\end{array}$ & NS & NS & NS \\
\hline Heel sole & $\begin{array}{c}p=0.000 \\
F(1,14)=25.002\end{array}$ & 74.1 & $\begin{array}{c}p=0.021, \\
F(4,56)= \\
7.956\end{array}$ & NS & NS & NS \\
\hline $\begin{array}{l}\text { Overall } \\
\text { comfort }\end{array}$ & $\begin{array}{c}p=0.000 \\
F(1,14)=26.450\end{array}$ & 100.7 & $\begin{array}{c}p=0.001, \\
F(4,56)= \\
5.726\end{array}$ & $\begin{array}{l}35 \vee 75 \\
55 \vee 65 \\
55 \vee 75\end{array}$ & $\begin{array}{l}0.008 \\
0.040 \\
0.000\end{array}$ & $\begin{array}{c}80 \\
60.6 \\
98.9\end{array}$ \\
\hline $\begin{array}{l}\text { Overall } \\
\text { length }\end{array}$ & $\begin{array}{c}p=0.019, \\
F(1,14)=7.052\end{array}$ & 56.9 & $\begin{array}{c}p=<.001, \\
F(4,56)= \\
6.619\end{array}$ & $\begin{array}{l}35 \vee 45 \\
35 \vee 75 \\
55 \vee 75\end{array}$ & $\begin{array}{l}0.045 \\
0.003 \\
0.001\end{array}$ & $\begin{array}{c}78.5 \\
116.7 \\
71.8\end{array}$ \\
\hline $\begin{array}{l}\text { Overall } \\
\text { width }\end{array}$ & $\begin{array}{c}p=0.001 \\
F(1,14)=17.415\end{array}$ & 99 & $\begin{array}{c}p=0.009, \\
F(4,56)= \\
3.778\end{array}$ & $\begin{array}{l}35 \vee 75 \\
55 \vee 75\end{array}$ & $\begin{array}{l}0.006 \\
0.030\end{array}$ & $\begin{array}{l}89.4 \\
51.9\end{array}$ \\
\hline Toes & $\begin{array}{c}p=0.003 \\
F(1,14)=13.206\end{array}$ & 66.2 & $\begin{array}{c}p=<.001 \\
F(4,56)= \\
9.788\end{array}$ & $\begin{array}{l}35 \vee 65 \\
35 \vee 75 \\
45 \vee 75 \\
55 \vee 75\end{array}$ & $\begin{array}{l}0.039 \\
0.000 \\
0.007 \\
0.011\end{array}$ & $\begin{array}{l}121.6 \\
154.3 \\
80.5 \\
79.1\end{array}$ \\
\hline $\begin{array}{l}\text { Under the } \\
\text { arch }\end{array}$ & $\begin{array}{c}p=0.081 \\
F(1,14)=3.525\end{array}$ & NS & $\begin{array}{c}p=<.001, \\
F(4,56)=9.392\end{array}$ & $\begin{array}{l}35 \vee 65 \\
35 \vee 75 \\
45 \vee 75 \\
55 \vee 75\end{array}$ & $\begin{array}{l}0.011 \\
0.000 \\
0.033 \\
0.000\end{array}$ & $\begin{array}{l}140.2 \\
171.3 \\
61.2 \\
62.8\end{array}$ \\
\hline
\end{tabular}

Where NS is not significant therefore not reported 


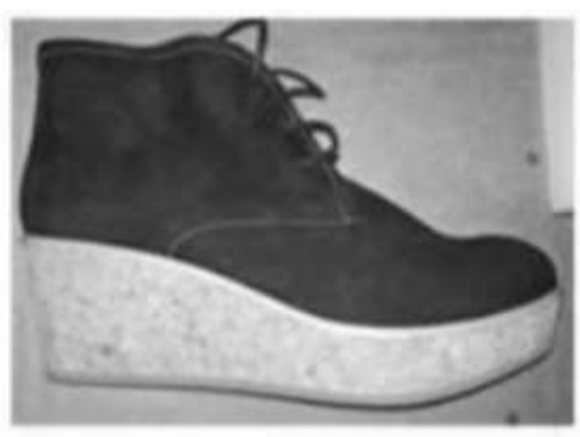

$35 \mathrm{~mm}$

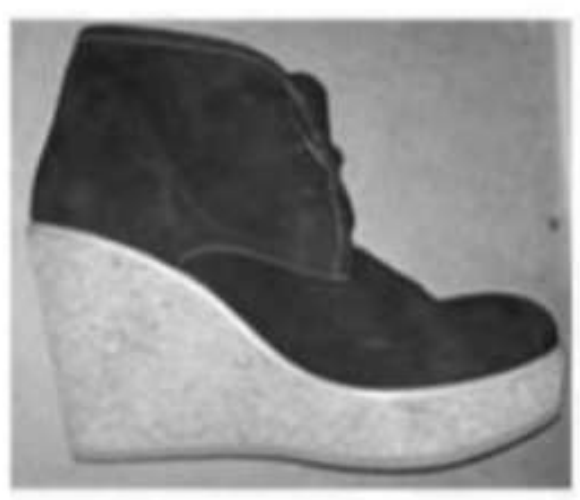

$75 \mathrm{~mm}$

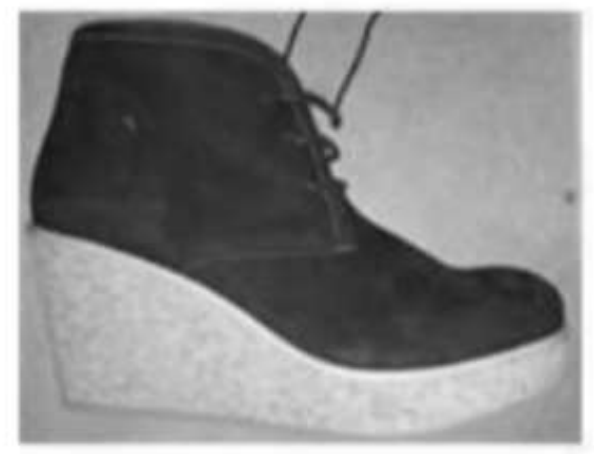

$55 \mathrm{~mm}$

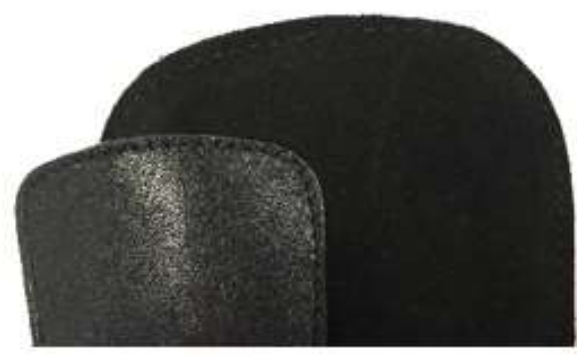

Upper materials

Figure 1. Example of footwear height conditions tested within this protocol (Soft upper) and upper materials utilised (stiff/leather front and soft/suede behind). 

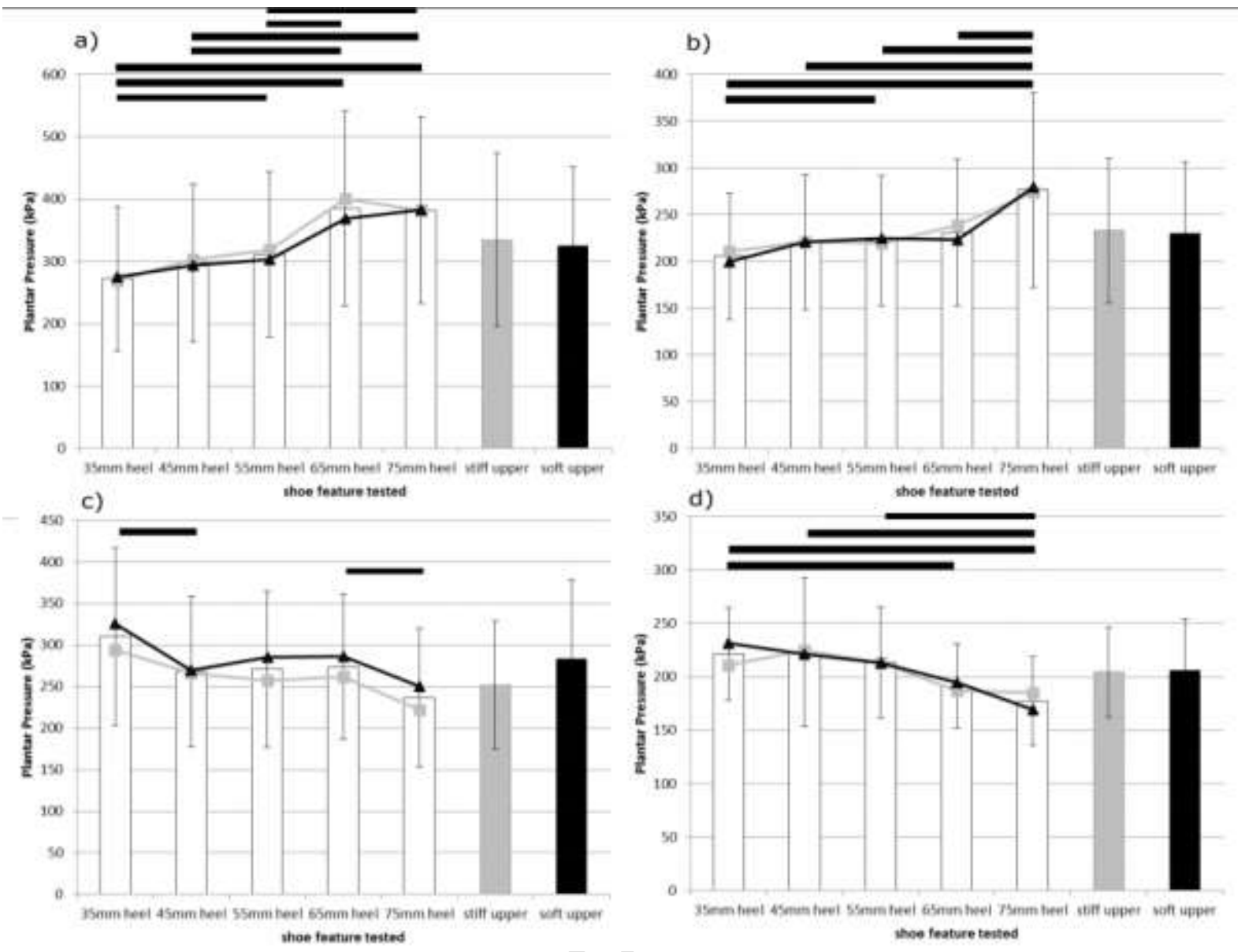

Figure 2. Bar chart denotes mean and SD of plantar pressure for each heel height condition and upper stiffness condition tested via ANOVA. The line graph displays the interaction effect between heel height $(35,45,55,65,75)$ and upper stiffness (soft and stiff) for each foot region: Hallux (a), MTP1 (b), MT24 (c) and Heel (d). Significant differences between conditions are identified using a horizontal line. 

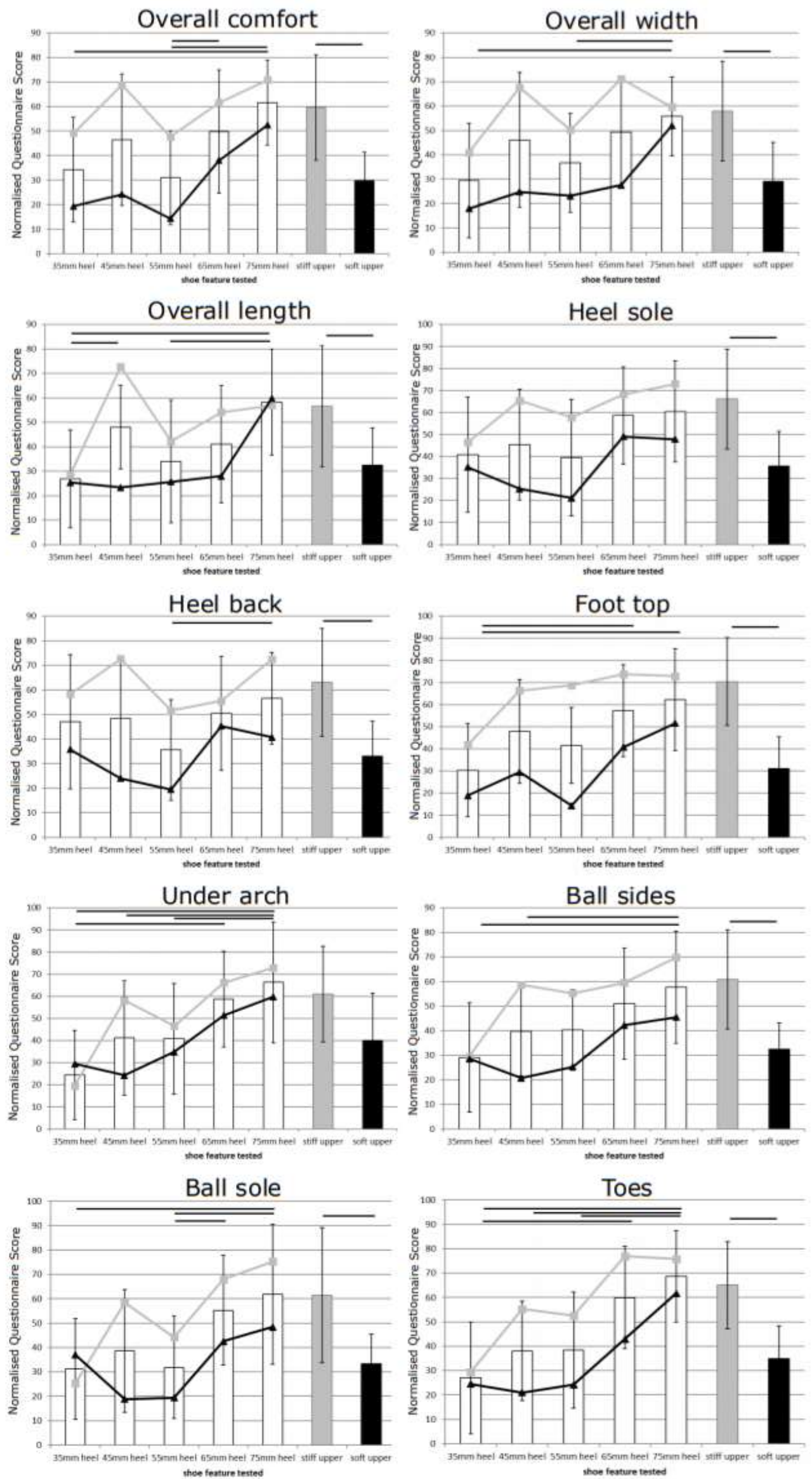
Figure 3. Bar chart denotes mean and SD of Comfort questionnaire for each heel height condition and upper stiffness condition tested via ANOVA. The line graph displays the interaction effect between heel height $(35,45,55,65,75)$ and upper stiffness (soft and stiff) for each foot region: Hallux (a), MTP1 (b), MT24 (c) and Heel (d). Significant differences between conditions are identified using a horizontal line. 